\title{
Malaria causes long-term effects on markers of iron status in children: a critical assessment of existing clinical and epidemiological tools
}

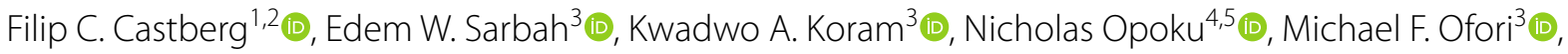
Bjarne Styrishave ${ }^{6}$, Lars Hviid ${ }^{1,7}(\mathbb{0})$ and Jørgen A. L. Kurtzhals ${ }^{1,2^{*}}$ (1)

\begin{abstract}
Background: Most epidemiological studies on the interplay between iron deficiency and malaria risk classify individuals as iron-deficient or iron-replete based on inflammation-dependent iron markers and adjustment for inflammation by using C-reactive protein (CRP) or a-1-acid glycoprotein (AGP). The validity of this approach and the usefulness of fibroblast growth factor 23 (FGF23) as a proposed inflammation-independent iron marker were tested.

Methods: Conventional iron markers and FGF23 were measured in children with acute falciparum malaria and after $1,2,4$, and 6 weeks. Children, who were transfused or received iron supplementation in the follow-up period, were excluded, and iron stores were considered to be stable throughout. Ferritin levels 6 weeks after admission were used as a reference for admission iron status and compared with iron markers at different time points.

Results: There were long-term perturbations in iron markers during convalescence from acute malaria. None of the tested iron parameters, including FGF23, were independent of inflammation. CRP and AGP normalized faster than ferritin after malaria episodes.
\end{abstract}

Conclusion: Malaria may bias epidemiological studies based on inflammation-dependent iron markers. Better markers of iron status during and after inflammation are needed in order to test strategies for iron supplementation in populations at risk of malaria.

Keywords: Iron deficiency, Malaria, Hepcidin, FGF23, Ferritin

\section{Background}

The geographical distributions of iron deficiency and malaria overlap. Iron deficiency has a negative impact on child development [1-4], but may also be associated with reduced susceptibility to infections because iron is essential for the growth of micro-organisms [5]. In line with this, an increasing number of epidemiological studies suggest that iron deficiency has a protective effect

\footnotetext{
*Correspondence: joku@sund.ku.dk

${ }^{1}$ Centre for Medical Parasitology, Department of Immunology and Microbiology, Faculty of Health and Medical Sciences, University of Copenhagen, Copenhagen, Denmark

Full list of author information is available at the end of the article
}

against malaria [6-10]. However, these studies have used conventional inflammation-dependant biomarkers, such as ferritin, as indicators of iron status, although they are known to be modified (usually increased) by malaria [11, 12]. The studies may therefore be biased due to iron status misclassification of study subjects.

Correspondingly, iron supplementation has been associated with increased risk of malaria, e.g., in the widely cited Pemba trial, which showed that routine iron supplementation resulted in increased morbidity and mortality among participating children [13]. Although some other studies have failed to confirm this finding [14], it remains 
a matter of dispute how to safely treat iron deficiency in areas where malaria is endemic.

Conventionally, serum ferritin has been used as the key iron marker as it reflects total body iron storage. However, ferritin is also an acute phase protein [15], so in an acute inflammatory situation, such as during malaria, serum ferritin levels may not accurately reflect body iron stores. In the present study, a time-series study of iron biomarkers was performed, as called for in the recent BRINDA study of anaemia in the context of inflammation [16]. Iron status was assumed to be stable during the study period for each study subject provided he or she did not receive a blood transfusion or iron supplementation. Thus, the intention was to use ferritin levels after normalization post infection as an indication of the true iron status during an acute malaria attack.

Using this reference point, the possibility that other iron markers during acute malaria might be correlated with ferritin after normalization was studied. The main focus was on hepcidin and fibroblast growth factor 23 (FGF23). Hepcidin is a peptide hormone that is regulated by iron stores, inflammation and erythropoietic demand and controls iron efflux from most cells in the body, in particular enterocytes and macrophages. Hepcidin has been suggested as the best marker to guide iron treatment as it has been proposed to be a key determinant of iron utilization $[17,18]$. Yet, hepcidin was found to be a poor predictor of bone marrow iron deficiency and of iron incorporation in severely anaemic Malawian children [19]. FGF23, a bone-derived hormone regulating vitamin $\mathrm{D}$ and phosphate homeostasis, has been proposed as an inflammation-independent iron marker in a single epidemiological study [20]. In the present study, the aim was to investigate if FGF23 was independent of inflammation in acute malaria.

\section{Methods}

\section{Ethical statement}

The study was approved by the Noguchi Memorial Institute for Medical Research Institutional Review Board (NMIMR STC Number: STC Paper 5(1) 2013-2014) and by the Ethical Review Committee of the Ghana Health Service (file GHS-ERC 08/05/14). Parents/guardians of all study participants were informed in their local language, Ewe, of the goals, benefits and risks of taking part in the study, and written consent was obtained prior to enrolment.

\section{Study site and participants}

The study was conducted in Hohoe, a town located about $220 \mathrm{~km}$ northeast of Accra, in an area of tropical, semi-deciduous, forest vegetation and used a convenience sample of children included in the MAVARECA study (Malaria Vaccine and Research Capacity Building in Ghana) [21]. Malaria transmission intensity in the area is high and has two seasonal peaks: a major one in April-July and a minor one in September-November [22]. Study participants were enrolled at Hohoe Municipal Hospital, June-August 2014 (pilot study) and June-August 2015.

Inclusion criteria were age 1-12 years, positive Plasmodium falciparum rapid diagnostic test (RDT), microscopic finding of peripheral parasitaemia $>2500$ infected erythrocytes (IEs) $/ \mu \mathrm{L}$, fever $\left(\geq 37.5^{\circ} \mathrm{C}\right)$ within the first $24 \mathrm{~h}$ of admission or a history of fever in the preceding $24 \mathrm{~h}$. Subjects were excluded if they had severe co-morbidity, including sickle-cell disease, or received a blood transfusion during admission due to severe anaemia (haemoglobin $(\mathrm{Hb})<5 \mathrm{~g} / \mathrm{dL}$ ) as the iron content of the transfused erythrocytes would otherwise distort the interpretation of the analysis of iron marker kinetics during follow up. During the follow-up period, patients were excluded if they presented with malaria, other severe disease or new spikes in inflammatory markers (C-reactive protein $(\mathrm{CRP})>5 \mathrm{mg} / \mathrm{L}$ or $\alpha$-1-acid glycoprotein $(\mathrm{AGP})>1 \mathrm{~g} / \mathrm{L}$ ), or had taken iron supplementation (only excluded after such an event). The reason for excluding these patients was that these events would have affected day- 42 results and thus the final endpoint.

Upon enrolment, a project nurse and physician completed a standardized questionnaire and performed a clinical examination. Severe malaria was defined according to WHO criteria [23]. Uncomplicated malaria cases were treated with a 3-day course of oral artemether-lumefantrine (AL), while severe malaria cases were treated with intravenous quinine for at least $24 \mathrm{~h}$ until oral AL was tolerated as follow-on therapy. In severe cases, ceftriaxone was given as empiric therapy for possible sepsis.

The patients were followed for 6 weeks and attended the research clinic 14 and 42 days post-admission (regular follow-up group). A sub-set of patients living near the hospital were also asked to come 7 and 28 days post-admission (frequent follow-up group). At follow-up visits, the patients or their parents were systematically interviewed about new symptoms and medicine use, including iron supplements, during the follow-up period. A missed follow-up appointment did not exclude the patient from future follow-up visits. Patients were encouraged to attend the research clinic at any time during the follow-up period if they developed any new symptoms.

For the purpose of this study, inflammation was defined as either CRP $>5 \mathrm{mg} / \mathrm{L}$ or $\mathrm{AGP}>1 \mathrm{~g} / \mathrm{L}$, while 
iron deficiency was defined as ferritin concentrations $<15 \mu \mathrm{g} / \mathrm{L}$ on day 42 .

\section{Laboratory methods}

Venous blood $(6 \mathrm{~mL})$ was collected in lithium-heparin- and EDTA-coated tubes at each of the above time points. A WHO-approved RDT kit and Giemsa-stained blood smears were used to assess malaria infection status, and $\mathrm{Hb}$ (reference range 11-18 $\mathrm{g} / \mathrm{dL}$, coefficient of variation $(\mathrm{CV})<4 \%)$, mean corpuscular volume $(\mathrm{MCV}$, 76-96 fL, $\mathrm{CV}<5 \%$, mean corpuscular $\mathrm{Hb}$ concentration (MCHC, 31-36 g/dL, CV $<6 \%$ ), mean corpuscular $\mathrm{Hb}(\mathrm{MCH}, 27-30 \mathrm{pg}, \mathrm{CV}<5 \%)$, red cell distribution width (RDW-CV, $<14.6 \%, C V<15 \%$ ) were measured using a Sysmex XS 500i. Remaining plasma was separated by centrifugation and stored frozen at $-80{ }^{\circ} \mathrm{C}$ until further analysis. Plasma hepcidin concentrations $(0.6-13.9 \mathrm{nmol} / \mathrm{L}, \mathrm{CV}<11 \%)$ were determined by mass spectrometry. Sample preparation was done in Eppendorf Lobind tubes (Sigma Aldrich, Søborg, Denmark) and all work was done under anaerobic conditions. Briefly, heparin plasma and internal standard [hep-25, Peptides International (Louisville, KY, USA)] was mixed with Macro-Prep ${ }^{\circledR}$ CM Weak Cation Exchange (WCX) beads (Bio-Rad, Hercules, CA, USA) and ammonium acetate at $\mathrm{pH}$ 7.5. After washing, the analyte was eluted with $25 \mu \mathrm{L}$ 2.5\% Trifluoroacetic acid, 50\% Acetonitrile LC-MS Chromasolv solution (both from Sigma-Aldrich) and the WCX beads were separated from supernatant by centrifugation at $500 \mathrm{~g}$. Peptide spectra were then generated on a Microflex matrix-enhanced laser desorption/ ionization (MALDI) TOF-MS platform (Bruker Daltonics, Bremen, Germany). Levels of FGF23 $(<125 \mathrm{RU} / \mathrm{mL}$, CV 2.4\%) were measured in duplicates using a 2nd generation, C-terminal, two-site ELISA (Immutopics Inc, CA, USA). Biochemical parameters (reference ranges), including AGP $(\leq 1 \mathrm{~g} / \mathrm{L})$, bilirubin $(4-22 \mu \mathrm{mol} / \mathrm{L})$, high sensitivity CRP $(\leq 5 \mathrm{mg} / \mathrm{L})$, fe $(5-30 \mu \mathrm{mol} / \mathrm{L})$, ferritin $(15-140 \mu \mathrm{g} / \mathrm{L})$, haptoglobin $(0.3-1.8 \mathrm{~g} / \mathrm{L})$, lactate dehydrogenase (LDH, 150-400 U/L), transferrin (18.7$50 \mu \mathrm{mol} / \mathrm{L})$, and transferrin saturation $(20-50 \%)$ were analysed on a Cobas 8000, (Roche, Rotkreuz, Switzerland, all $\mathrm{CV}<7 \%$ ). Levels of soluble transferrin receptor (sTfR, 0.76-1.76 mg/L, 3.6-4.3\%) were measured (2014 samples only) in duplicates by BNII nephelometry (Siemens, Munich, Germany). Sickle cell Hb phenotype was determined by electrophoresis, while glucose-6-phosphate dehydrogenase (G6PD) deficiency was determined by methylene blue reduction test [24] (day 42 samples only).

Urine $(>12 \mathrm{~mL})$ was collected at enrolment and tested for signs of microscopic haematuria and urinary tract infections using Siemens Multistix ${ }^{\circledR} 10$ SG. Microscopy analysis of all 2014 pilot urine samples yielded no positive results for Schistosoma haematobium eggs. In 2015, only samples with dipstick data suggesting haematuria were assessed by microscopy.

Stool samples $(>4 \mathrm{~mL})$ were collected during admission. At least $2 \mathrm{~mL}$ were stored frozen (for later PCR detection of infection by Cryptosporidium, Giardia lamblia and Entamoeba histolytica), while at least $2 \mathrm{~mL}$ were mixed with formalin (10\%) and stored at room temperature for later formalin-ether concentration (a.m. Ridley) and microscopy for cysts, helminth larvae and eggs.

\section{Statistical analysis}

Data were double-entered in a Microsoft Access database. Mismatches were resolved by consultation of the original records. Statistical analyses were done in SAS v. 9.4 (SAS Institute, NC, USA). All continuous variables are presented as geometric means \pm 2 standard deviations (SD), unless otherwise specified. Longitudinal data were analysed using log-transformed variables in a mixed effects model. P values $<0.05$ were considered statistically significant. As some CRP values were 0 , i.e., below the lower detection level of 1 , " 1 " was added to the CRP value before log transformation. Pearson's correlation coefficient $(\mathrm{R})$ was used to determine correlation between logtransformed iron markers.

Only data collected \pm 2 days from the scheduled follow-up date were included, except for day 42, where delays in data collection were tolerated (six samples were collected after day 44, the latest on day 51 ).

\section{Results}

A total of 156 patients with a positive RDT were recruited to participate in the study. Three patients did not meet the fever criteria, one was excluded due to sickle cell disease, 40 had $\leq 2500 \mathrm{IEs} / \mu \mathrm{L}$ on presentation, and 14 patients received a blood transfusion during admission on clinical indication or because their $\mathrm{Hb}$ levels decreased to $<5 \mathrm{~g} / \mathrm{dL}$. The analysis is restricted to the 98 remaining patients (Fig. 1). A summary of the study population characteristics can be found in Table 1.

Twenty-four patients were excluded during followup: 16 had re-infection or recrudescence, while 8 developed new spikes in inflammatory markers. Eight patients never attended a follow-up visit, and 12 other patients were lost to follow-up by day 42. Fifty-four patients, who had normal inflammatory marker levels on day 42 were retained in the study (Fig. 1). No statistical differences in age, gender and iron or inflammatory parameters on day 0 were detected between the 54 patients who completed the study and the 44 who did not. Similarly, no significant differences in gender and iron or inflammatory parameters on day 0,14 and 42 were noted between the regular 


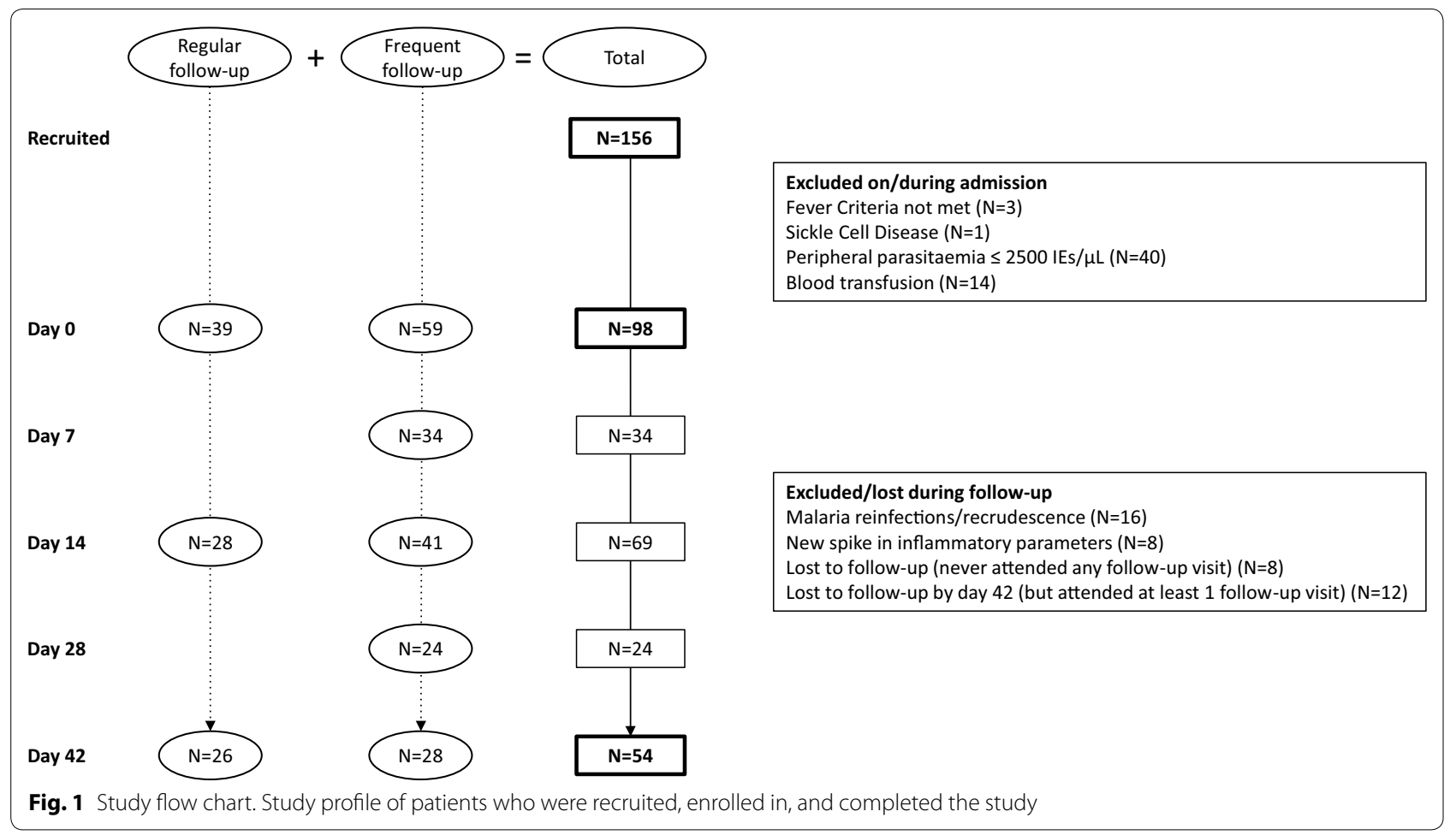

follow-up group $(\mathrm{N}=39)$ and the frequent follow-up group $(\mathrm{N}=59)$. Patients scheduled for frequent followup were 1 year older (geometric mean age 4.2 vs 3.3, $\mathrm{P}=0.03$ ), but had similar gender distribution compared with the children in the regular follow-up group. Twentyone samples were excluded as they were taken outside the predefined follow-up window ( \pm 2 days of scheduled visits).

On admission, $76 \%$ of the included patients were mildly ( $\mathrm{Hb} 8-11 \mathrm{~g} / \mathrm{dL}$ ) or moderately (Hb $5-8 \mathrm{~g} / \mathrm{dL}$ ) anaemic. (Patients with severe anaemia $(\mathrm{Hb}<5 \mathrm{~g} / \mathrm{dL})$ were excluded). Hb levels decreased until day 7 post-admission despite treatment, but had returned to normal levels by day 28 (Fig. 2a). Indicators of haemolysis (low haptoglobin levels, Fig. 2b) and high levels of bilirubin (Fig. 3a) and lactate dehydrogenase (LDH) (Fig. 3b) followed this pattern. Erythropoiesis appeared to be suppressed (low RDW) at admission, and was followed by signs of increased erythropoiesis on day 7 (Fig. 2c), in agreement with an earlier study [25].

Ferritin levels were high on day 0 and gradually decreased during follow-up, including a statistically significant drop between day 28 and day 42 (Fig. 4a). Ferritin levels on day 42 had been selected as an indicator of the iron status throughout the study period, and the kinetics curve (Fig. 2a) supported the assumption that decreases beyond that day would be minimal.
Four of the children (8\%) were iron-deficient (ferritin concentrations below $<15 \mu \mathrm{g} / \mathrm{L}$ on day 42$)$. The acute phase proteins CRP (Fig. 4b) and AGP (Fig. 4c) are commonly used to compensate for the effect of inflammation when ferritin levels are used to detect iron deficiency [16, $26,27]$. Similar to ferritin, they were raised on day 0 and gradually fell, but they normalized faster than ferritin with no detectable difference between day 28 and day 42 levels.

FGF23 levels were significantly elevated on day 0 , and thus not independent of inflammation as previously claimed [20]. Day 0 levels of FGF23 showed a dichotomized distribution and were poorly correlated with CRP and AGP levels $[R=0.05(P=0.03), R=0.03(P=0.08)$, respectively]. Levels had normalized by day 7 and remained stable throughout the remaining observation period (Fig. 5). Yet, even after it had normalized, FGF23 levels on days 14, 28 and 42 remained poorly correlated with ferritin levels on day $42[R=-0.58(P<0.0001)$, $\mathrm{R}=-0.56 \quad(\mathrm{P}=0.02), \quad$ and $\quad \mathrm{R}=-0.51 \quad(\mathrm{P}=0.0001)$, respectively].

Classic markers used in anaemia work-up, such as MCV (Fig. 6a), MCHC (Fig. 6c) and MCH (Fig. 6e), were all stable throughout the observation period and the regression analysis between day 0 and day 42 values were close to the identity line (Fig. $6 \mathrm{~b}, \mathrm{~d}, \mathrm{f}$ ), indicating that measurements on day 0 were predictive of measurements 
Table 1 Study population characteristics

\begin{tabular}{|c|c|c|}
\hline Description & $\mathbf{N}$ & Value \\
\hline \multicolumn{3}{|l|}{ Child characteristics } \\
\hline Age (geometric mean, range) & 97 & 3.8 years $(1 ; 12)$ \\
\hline Age $<60$ months & 97 & 63 \\
\hline Female & 98 & 44 \\
\hline \multicolumn{3}{|l|}{ Nutritional status } \\
\hline Height (mean \pm 2SD) & 71 & 98 cm $(69.2 ; 128.6)$ \\
\hline Weight (geometric mean \pm 2SD) & 98 & $14.4 \mathrm{~kg}(7.7 ; 26.6)$ \\
\hline Stunted (children $<60$ months) ${ }^{\mathrm{a}}$ & 45 & $13(29 \%)$ \\
\hline Underweight (children $<60$ months) ${ }^{\mathrm{a}}$ & 63 & $11(17 \%)$ \\
\hline Low BMI-for-age (children $>60$ months) ${ }^{b}$ & 26 & $8(31 \%)$ \\
\hline \multicolumn{3}{|l|}{ Admission } \\
\hline Hospital admission (yes/no) & 98 & $60 / 38$ \\
\hline Admission length (median, IQR) & 60 & 3 days $(2 ; 4)$ \\
\hline Clinical malaria (uncomplicated/severe) & 98 & $68 / 30$ \\
\hline Clinical co-infection on presentation (yes/no) ${ }^{c}$ & 98 & $22 / 76$ \\
\hline \multicolumn{3}{|l|}{ Laboratory parameters } \\
\hline Malaria parasitaemia on presentation (geometric mean \pm 2SD) & 98 & $\begin{array}{l}\text { 40,326 IEs/ML (3465; } \\
469,356)\end{array}$ \\
\hline Haemoglobin on presentation (geometric mean $\pm 2 S D$ ) & 98 & $9.5 \mathrm{~g} / \mathrm{dL}(6.7 ; 13.5)$ \\
\hline Anaemia level on presentation (no anaemia/mild/moderate) ${ }^{d}$ & 98 & $24 / 60 / 14$ \\
\hline Iron deficiency on day 42 (ferritin $<15 \mu \mathrm{g} / \mathrm{L}$ ) & 52 & 4 \\
\hline Glucose-6-phosphate dehydrogenase deficiency (normal enzyme activity/partial defect/full defect) ${ }^{e}$ & 54 & $39 / 4 / 11$ \\
\hline Sickle cell genotype (AA/AC/AF/AS) & 98 & $85 / 8 / 2 / 3$ \\
\hline Raised C-reactive protein on day 0 (>5 mg/L) & 94 & 93 \\
\hline Raised a-1-acid glycoprotein on day 0 (> $1 \mathrm{~g} / \mathrm{L})$ & 92 & 90 \\
\hline Positive stool microscopy for anaemia-causing pathogenic organisms ${ }^{\mathrm{f}}$ & 74 & 4 \\
\hline Antimalarial treatment prior to hospital attendance & 98 & 19 \\
\hline $\begin{array}{l}\text { Antimalarial treatment prescribed (quinine i.v. + artemether-lumefantrine follow-on/artemether-lumefan- } \\
\text { trine only) }\end{array}$ & 98 & $44 / 54$ \\
\hline \multicolumn{3}{|c|}{$\mathrm{N}=$ Number of children; Value $=$ Number of children unless otherwise specified } \\
\hline \multicolumn{3}{|c|}{ a Stunting and underweight are defined as height-for-age and weight-for-age, respectively, $<-2$ standard deviations of the WHO Growth Reference [46] } \\
\hline \multicolumn{3}{|c|}{ b Low BMI-for-age is defined as BMI-for-age $<-2$ standard deviations of the WHO Growth Reference [46] } \\
\hline \multicolumn{3}{|c|}{$\begin{array}{l}\text { c Dermatitis }(N=2) \text {, gastroenteritis }(N=10) \text {, lower respiratory tract infections }(N=3) \text {, suspected sepsis }(N=2) \text {, upper respiratory tract infections }(N=2) \text {, urinary tract } \\
\text { infections }(N=3)\end{array}$} \\
\hline \multicolumn{3}{|c|}{ d No anaemia (Hb $\geq 11 \mathrm{~g} / \mathrm{dL})$, mild anaemia (Hb 8-11 g/dL), moderate anaemia (Hb 5-8 g/dL) } \\
\hline \multicolumn{3}{|l|}{ e Tested on day 42} \\
\hline h Hookworm. Hymer & & \\
\hline
\end{tabular}

on day 42 on study subject level. One MCHC measurement deviated far from all others without any other noticeable characteristics of this patient. This value was considered a measurement error and was omitted in the data analysis.

Malaria causes haemolytic anaemia that does not affect MCV, MCHC or MCH. Nevertheless, these markers all correlated poorly with ferritin levels on day 42 [MCV: $\mathrm{R}=0.26$ ( $\mathrm{P}=0.07) ; \mathrm{MCH}: \mathrm{R}=0.30$ ( $\mathrm{P}=0.03), \mathrm{MCHC}$ : $\mathrm{R}=0.10(\mathrm{P}=0.49)$ ]. Furthermore, the slightly increased MCV values day 7 to day 28 (Fig. 6a) and the concomitant decrease in $\mathrm{MCHC}$ levels (Fig. 6c) likely reflect increased erythropoiesis during this period as indicated by the raised RDW on days 7 and 14, (Fig. 2c).

During the acute malaria attack (day 0), hepcidin levels were raised (Fig. 7a), which was reflected in low levels of Fe, transferrin and transferrin saturation (Fig. 7b-d). Levels of hepcidin, Fe, transferrin, as well as transferrin saturation had normalized by day 14 . Of all iron parameters, day 0 values of transferrin, transferrin saturation and ferritin had the best-yet weak-correlation with ferritin levels on day $42[R=-0.45(P=0.001)$, $\mathrm{R}=0.35(\mathrm{P}=0.01)$, and $\mathrm{R}=0.29(\mathrm{P}=0.04)$, respectively] (Fig. 8a-c). 

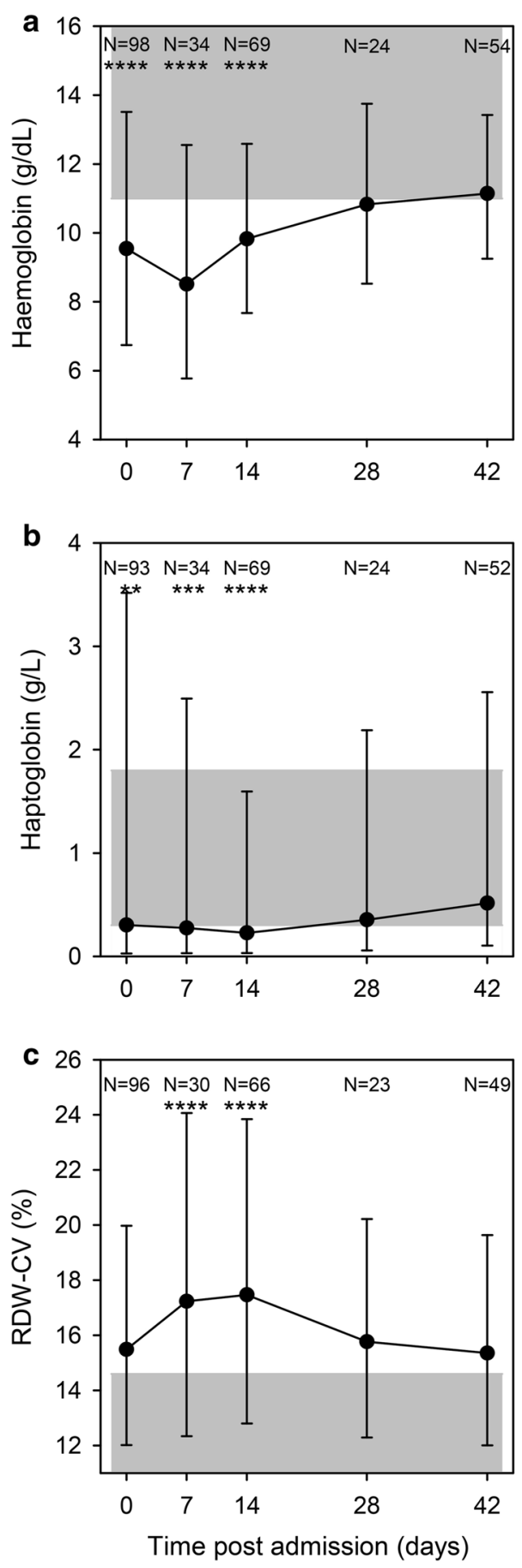

Fig. 2 Haematology. Haemoglobin (a), haptoglobin (b), and red cell distribution width-coefficient of variation (RDW-CV) (c) on days 0,7 , 14, 28, and 42 post-admission. Geometric means (filled circle) and standard deviations (bars) are shown. Number of samples $(\mathrm{N})$ and statistically significant differences $\left({ }^{*} P<0.05\right.$, ${ }^{* *} P<0.01$, ${ }^{* *} P<0.001$, $\left.{ }^{* * *} \mathrm{P}<0.0001\right)$ relative to day 42 are indicated along the top of each panel. Normal reference area is indicated by grey shading
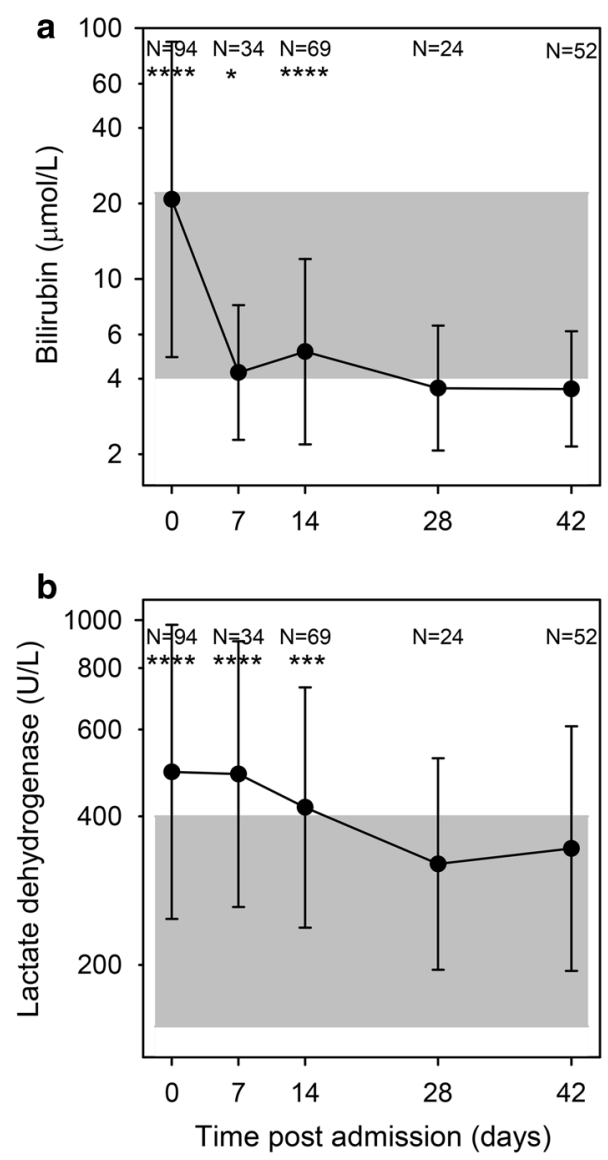

Fig. 3 Bilirubin and lactate dehydrogenase. Plasma levels of bilirubin (a) and lactate dehydrogenase (b) on days $0,7,14$, 28 , and 42 post-admission. Geometric means (filled circle) and standard deviations (bars) are shown. Number of samples $(\mathrm{N})$ and statistically significant differences $\left({ }^{*} P<0.05\right.$, ${ }^{* *} P<0.01$, ${ }^{* * *} P<0.001$, ****P<0.0001) relative to day 42 are indicated along the top of each panel. Normal reference area is indicated by grey shading

In the 2014 pilot study, sTfR, an indicator of erythropoietic intensity, was also measured on days 0,14 and 42 . Day 0-levels of sTfR levels were below the day 42 levels $(\mathrm{P}=0.0004)$, whereas day 14 levels were above day 42 levels $(\mathrm{P}=0.03)$, consistent with post-malarial erythropoiesis. sTfR/log ferritin ratios were not associated with ferritin levels on day 42 , why this parameter was omitted in the 2015 study.

On admission, patients with severe malaria had lower $\mathrm{Hb}(8.5$ vs $10.1 \mathrm{~g} / \mathrm{dL}, \mathrm{P}<0.0001)$, lower haptoglobin [0.16 vs $0.36 \mathrm{~g} / \mathrm{L},(\mathrm{P}=0.0001)]$, higher LDH [639 vs 445 $\mathrm{U} / \mathrm{L}(\mathrm{P}<0.0001)]$, and higher bilirubin $[26$ vs $19 \mu \mathrm{mol} / \mathrm{L}$ $(\mathrm{P}=0.005)]$, compared to patients with uncomplicated malaria, consistent with more pronounced haemolysis in the severe malaria group. Also, admission levels of ferritin and FGF23 were higher in patients with severe malaria [643 vs $365 \mu \mathrm{g} / \mathrm{L}(\mathrm{P}=0.002)$ and 647 vs $333 \mathrm{RU} /$ 

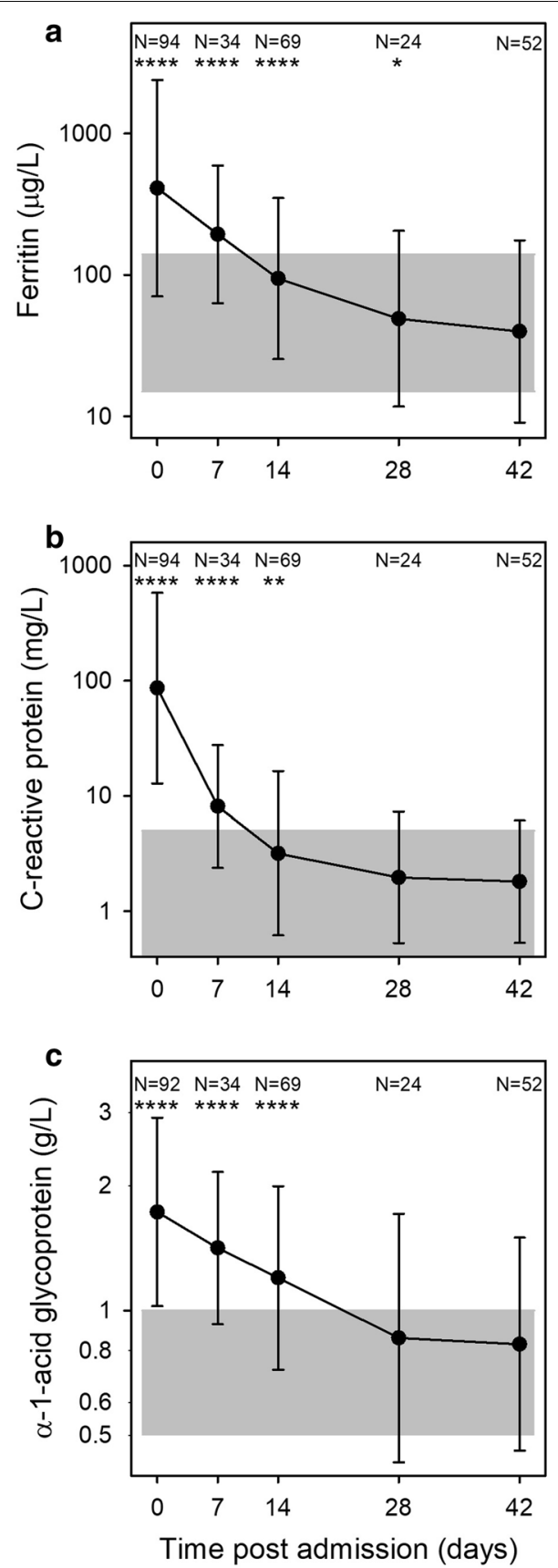

Fig. 4 Ferritin and inflammation markers. Plasma levels of ferritin (a), C-reactive protein, (b), and a-1-acid-glycoprotein (c) on days 0 , 7, 14, 28, and 42 post-admission. Geometric means (filled circle) and standard deviations (bars) are shown. Number of samples (N) and statistically significant differences $\left({ }^{*} P<0.05,{ }^{*} \mathrm{P}<0.01,{ }^{* * *} \mathrm{P}<0.001\right.$, $\left.{ }^{* * *} \mathrm{P}<0.0001\right)$ relative to day 42 are indicated along the top of each panel. Normal reference area is indicated by grey shading

$\mathrm{mL}(\mathrm{P}=0.02)$, respectively], likely due to inflammation. By day 7 , these differences were no longer detectable, except differences in haemoglobin levels that did not resolve until day 28 .

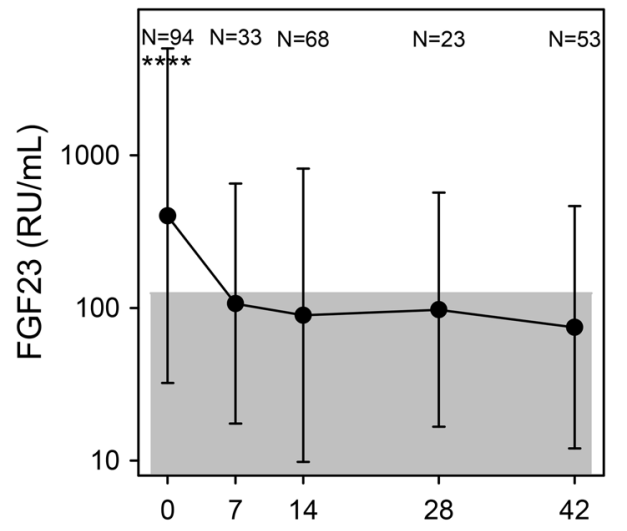

Fig. 5 Fibroblast growth factor 23 (FGF23). Plasma levels of FGF23 on days $0,7,14,28$ s and 42 post-admission on days 0,7 , 14,28 , and 42 post-admission. Geometric means (filled circle) and standard deviations (bars) are shown. Number of samples $(\mathrm{N})$ and statistically significant differences $\left({ }^{*} P<0.05,{ }^{* *} P<0.01\right.$, ${ }^{* *} P<0.001$, $\left.{ }^{* * *} \mathrm{P}<0.0001\right)$ relative to day 42 are indicated along the top of each panel. Normal reference area is indicated by grey shading

\section{Discussion}

In this observational, longitudinal study, conventional iron markers as well as FGF23 were measured in children on admission with acute falciparum malaria and after 1 , 2,4 and 6 weeks. The most striking finding was the duration of iron marker perturbations following episodes of falciparum malaria. Ferritin was elevated for more than 4 weeks after the infection in children without evidence of recrudescence or re-infection (Fig. 4a). This finding challenges the interpretation of previous epidemiological studies of iron deficiency in malaria-exposed populations, which have used various approaches to control for inflammation. Some studies have employed an upward adjustment of the cut-off for ferritin in case of raised CRP to levels $>8.2-10 \mathrm{mg} / \mathrm{L}[7,8]$, while others have used arithmetic correction factors based on CRP and AGP levels $[10,28,29]$. In the recent BRINDA study, it is advocated to use internal linear regression to correct ferritin concentrations based on CRP and AGP levels [27]. The fact that both CRP and AGP (Fig. 4b, c) normalized at least 2 weeks earlier than ferritin (Fig. 4a) suggests that this practice may not be sufficient to fully compensate for the effect of malaria on ferritin.

The only biomarkers of relevance to iron deficiency that were unaffected by the malaria-induced inflammation were $\mathrm{MCV}, \mathrm{MCHC}$ and $\mathrm{MCH}$ (Fig. 6a, c, e). These remained stable throughout the study period with the exception of temporary changes associated with erythropoiesis. This supports the assumption that the iron status of the children did not change markedly over the 6-week follow-up period and that the ferritin levels on day 42 are likely to reflect the true iron status on day 0 . However, 

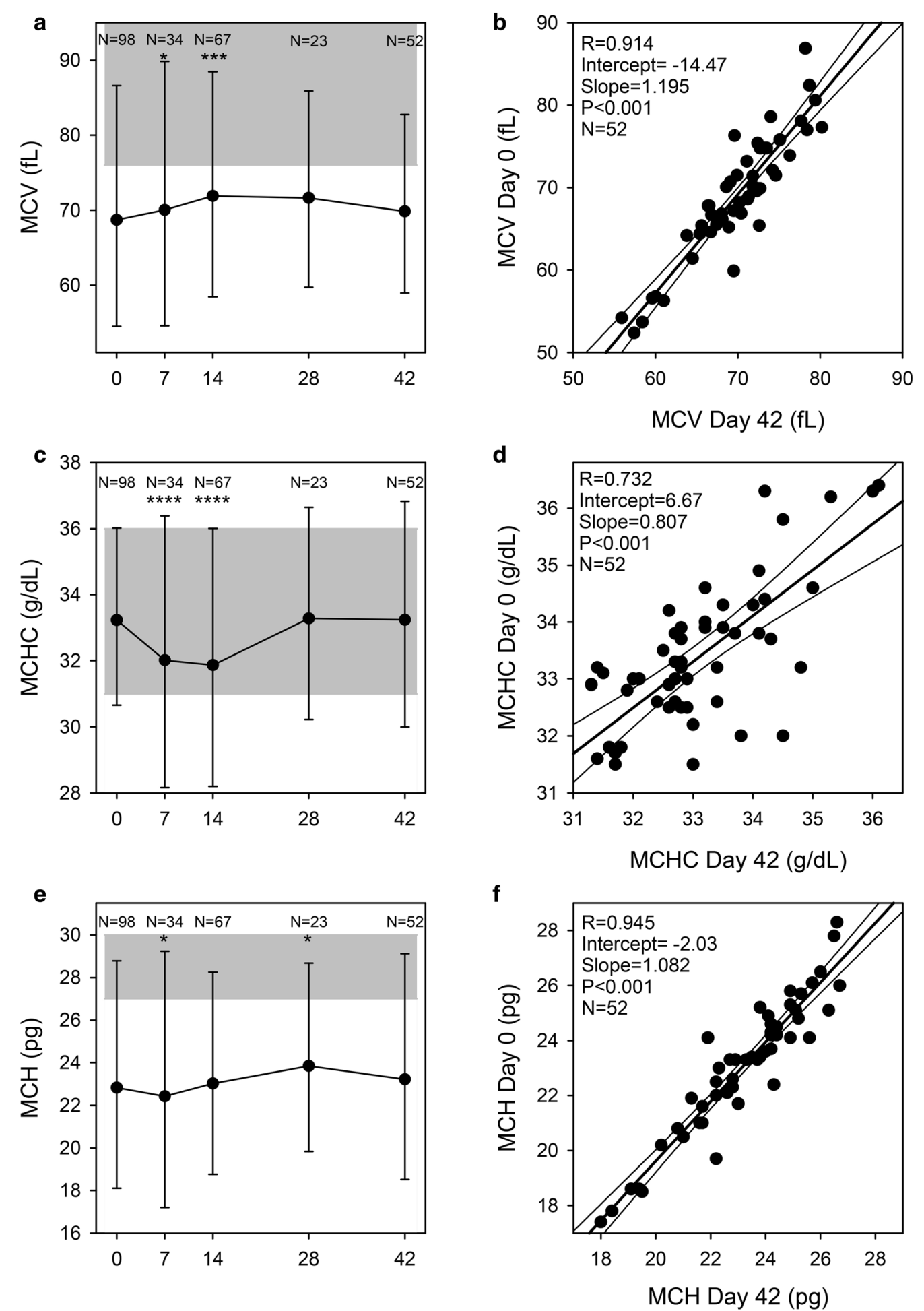

Fig. 6 Red cell indices. Mean corpuscular volume (MCV) (a), mean corpuscular haemoglobin concentration (MCHC) (c), and mean corpuscular haemoglobin (MCH) (e) on days 0, 7, 14, 28 and 42 post-admission. Geometric means (filled circle) and standard deviations (bars) are shown. Number of samples $(\mathrm{N})$ and statistically significant differences $\left({ }^{*} \mathrm{P}<0.05,{ }^{* *} \mathrm{P}<0.01,{ }^{* * *} \mathrm{P}<0.001,{ }^{* * * *} \mathrm{P}<0.0001\right)$ relative to day 42 are indicated along the top of each panel. Normal reference area is indicated by grey shading. Linear correlation of admission (day 0) and steady-state (day 42 ) data (b, d, f). Correlation between MCV, MCHC and MCH levels at admission (day 0) and at steady-state (day 42) (b, d, f). Individual data points (filled circle), and the associated linear regression line (with 95\% confidence interval) are shown. The linear correlation coefficient $\left(\mathrm{R}^{2}\right)$, its statistical significance, and the number of data points are indicated in the panel margin 

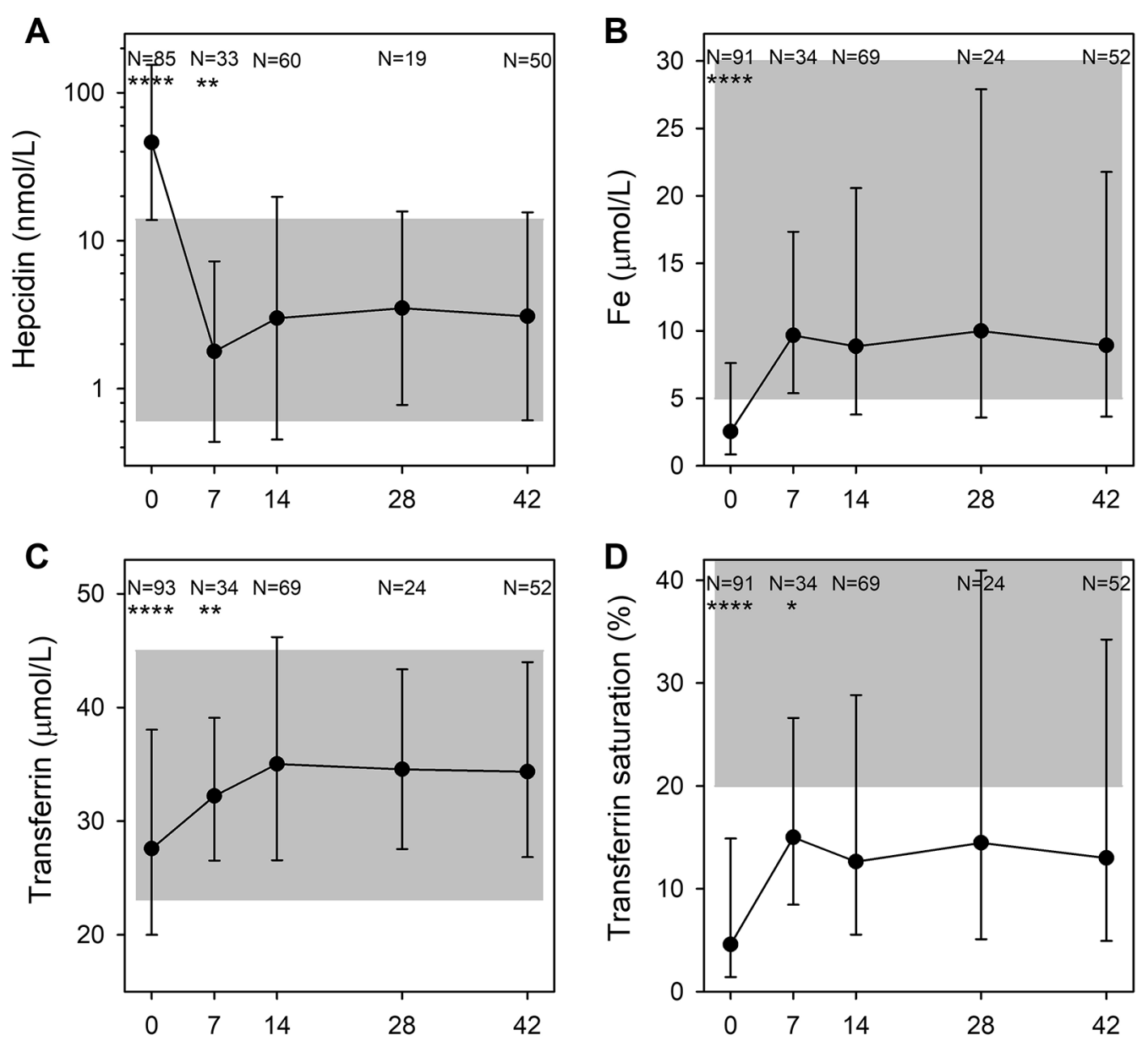

Fig. 7 Additional iron markers. Plasma levels of hepcidin (a), iron (Fe) (b), transferrin (c), and transferrin saturation (d) on days $0,7,14,28$, and 42 post-admission. Geometric means (filled circle) and standard deviations (bars) are shown. Number of samples (N) and statistically significant differences $\left({ }^{*} \mathrm{P}<0.05,{ }^{* *} \mathrm{P}<0.01,{ }^{* * *} \mathrm{P}<0.001,{ }^{* * * *} \mathrm{P}<0.0001\right.$ ) relative to day 42 are indicated along the top of each panel. Normal reference area is indicated by grey shading

$\mathrm{MCV}, \mathrm{MCHC}$ and $\mathrm{MCH}$ all correlated poorly with ferritin and are thus unlikely to be useful as markers of iron status in the absence of overt iron deficiency anaemia.

It could be argued that a further drop in ferritin may occur after day 42 . The time to normalization of ferritin after a range of clinical conditions has varied from 1 to 7 weeks, although this has not specifically been studied in malaria [30-33]. Forty-two days' follow-up time was selected, which is the standard follow-up time used in studies of anti-malarial drug resistance. Although the curve had clearly flattened at day 42 , the possibility of a longer lasting perturbation of ferritin following malaria cannot be ruled out, which would further question the use of ferritin as an indicator of iron deficiency in areas where malaria is endemic.

FGF23 is a bone-derived hormone involved in calciumphosphate homeostasis regulated by active vitamin $\mathrm{D}$ and phosphate, and more recently also noted to be stimulated by iron deficiency [34]. In The Gambia, a population study found that FGF23 was associated with iron status in children independently of inflammation (defined as elevated CRP) [20]. However, in the present study, FGF23 was markedly elevated in acute malaria (Fig. 5). This finding is in line with recent studies in humans [35] and in experimental malaria [36]. Moreover, even though FGF23 levels normalized already on day 7, i.e., much earlier than ferritin levels, FGF23 levels correlated poorly with day-42 plasma ferritin. Hence, it does not seem promising to further explore the possibility of using FGF23 as an inflammation-independent indicator of iron status.

Among the other iron markers tested in this study (day 0 values), transferrin showed the best correlation with ferritin on day $42[\mathrm{R}=-0.45(\mathrm{P}=0.001)]$. However, transferrin was also markedly affected by inflammation, and the correlation between transferrin day 42 levels with plasma ferritin levels on day 42 was modest. In the pilot 


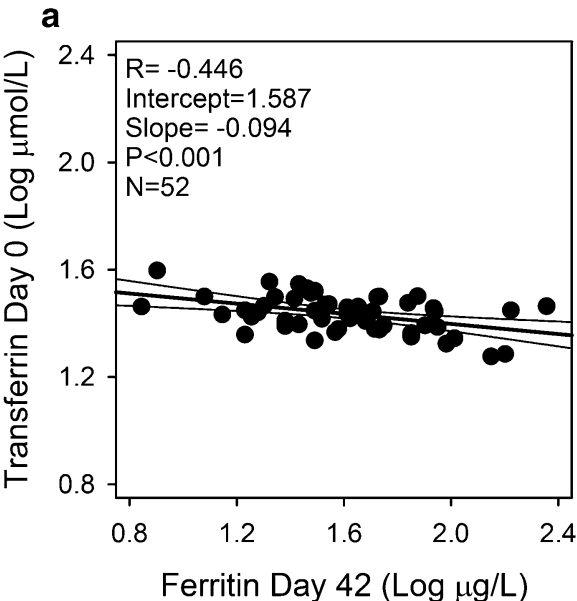

b
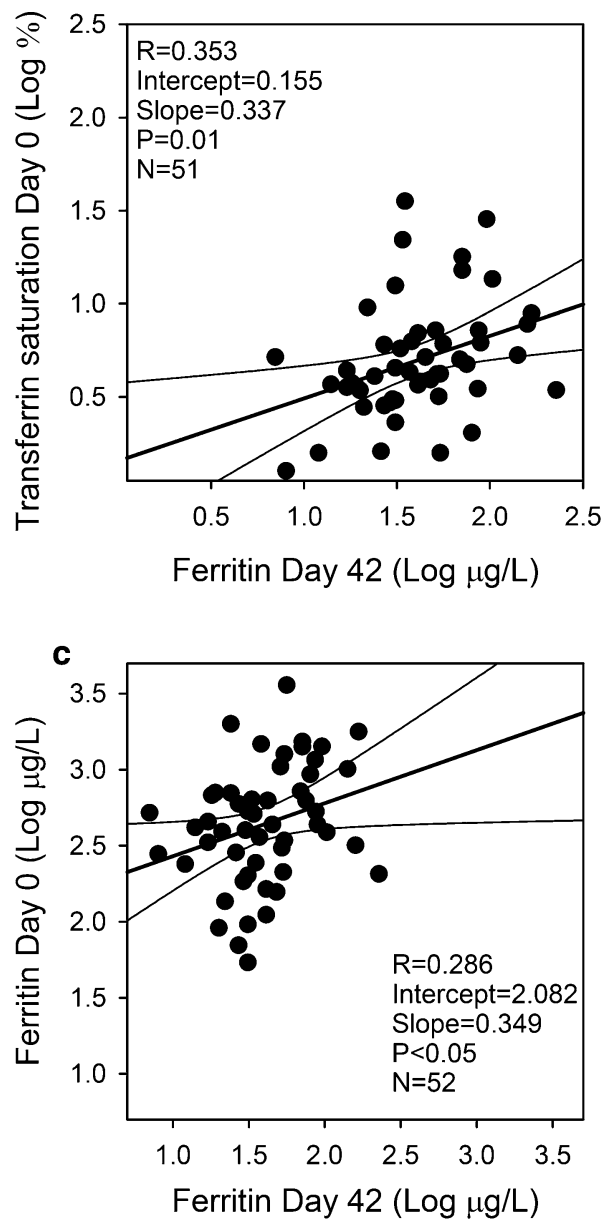

Fig. 8 The three iron markers with best day 0 correlations to ferritin levels on day 42. Linear regression plots of log-transformed values of transferrin (a), transferrin saturation (b) and ferritin (c) on admission (day 0) vs log-transformed ferritin levels at steady-state (day 42). Individual data points (filled circle), and the associated linear regression line (with 95\% confidence interval) are shown. The linear correlation coefficient $\left(R^{2}\right)$, its statistical significance, and the number of data points are indicated in the panel margin study, sTfR levels were also evaluated. This biomarker is less affected by inflammation than ferritin but increases in haemolytic anaemia [37, 38]. Levels of sTfR are also directly associated with parasitaemia, and its usefulness in acute malaria studies has therefore been questioned [39]. The present study data supports this concern. The wide variation among values obtained with different sTfR test kits are also of concern [17]. The ratio of soluble transferrin receptor to log ferritin concentrations (sTfR/ $\log$ ferritin index) has been suggested as a more precise iron marker, applying the reciprocal relationship between ferritin and sTfR [40], but the index suffers from the disadvantages of its parameters, i.e., their dependence of inflammation (ferritin) and erythropoiesis (sTfR).

The possibility that artemisinin-associated haemolysis might have enhanced perturbations of markers of erythropoiesis in the follow-up period was also considered. This condition is associated with hyperparasitaemia at the initiation of treatment [41]. In the present study, only 5 of 98 patients had over 250,000 malaria parasites/ $\mu \mathrm{L}$ on admission, and they all had higher concentrations of LDH on admission than at any time in the follow-up period, while haptoglobin remained below the detection threshold until day 42. Hence, artemisinin-associated haemolysis is unlikely to have affected the overall results.

The lack of an inflammation-independent marker of iron deficiency may restrict the possibility to develop innovative strategies for iron supplementation in malaria-endemic areas. Experimental studies suggest that the increased susceptibility to malaria in the course of iron supplementation is temporary [42]. In order to shorten a possible window of vulnerability, rapid reconstitution of iron stores with the use of intravenous ferric carboxymaltose has previously been suggested [43] This approach is supported by recent studies indicating that iron deficiency increases malaria mortality in mice and that intravenous iron given during acute malaria improves survival [36]. However, intravenous iron can cause iron overload, which is a safety hazard. Consequently, safe administration of intravenous iron requires targeting of patients with iron deficiency, and this would require an inflammation-independent marker for it to be used in children at risk of malaria.

The observed temporal changes in hepcidin levels are in line with previous studies [44]. During the acute phase of malaria, hepcidin was raised, indicating that inflammatory stimuli outweighed signals from the haemolytic anaemia of malaria. The drop in hepcidin levels day 7 (Fig. 7a) coincided with signs of increased erythropoiesis (Fig. 2c) and increased levels of plasma iron (Fig. 7b), and hepcidin remained low throughout the follow-up period. The low levels of hepcidin on day 7 indicate that oral iron supplementation would be effective shortly after recovery 
from malaria [45] and supports using hepcidin levels to guide iron therapy [17], although it cannot be used as a stand-alone marker of iron levels.

\section{Conclusion}

Better biomarkers for iron stores in acute malaria are still needed to improve the understanding of the interplay between iron status and malaria and to develop safe strategies for iron supplementation in areas where malaria is endemic.

\begin{abstract}
Abbreviations
AGP: a-1-acid glycoprotein; AL: artemether-lumefantrine; CRP: C-reactive protein; FGF23: fibroblast growth factor 23; G6PD: glucose-6-phosphate dehydrogenase; $\mathrm{Hb}$ : haemoglobin; IEs: infected erythrocytes; MCH: mean corpuscular haemoglobin; MCHC: mean corpuscular haemoglobin concentration; MCV: mean corpuscular volume; RDT: rapid diagnostic test; RDW-CV: red cell distribution width (coefficient of variation); sTfR: soluble transferrin receptor.
\end{abstract}

\section{Authors' contributions}

FCC, LH, JALK and KAK designed the study. FCC and EWS conducted the clinical research. NO, MFO and BS contributed to the laboratory analyses. FCC, LH and JALK analysed and interpreted the data, wrote the paper and had primary responsibility for final content. EWS, KAK, NO, MFO and BS revised the manuscript. All authors read and approved the final manuscript.

\begin{abstract}
Author details
${ }^{1}$ Centre for Medical Parasitology, Department of Immunology and Microbiology, Faculty of Health and Medical Sciences, University of Copenhagen, Copenhagen, Denmark. ${ }^{2}$ Centre for Medical Parasitology, Department of Clinical Microbiology, Copenhagen University Hospital (Rigshospitalet), Copenhagen, Denmark. ${ }^{3}$ Noguchi Memorial Institute for Medical Research, Accra, Ghana. ${ }^{4}$ Hohoe Municipality Hospital, Hohoe, Ghana. ${ }^{5}$ Present Address: School of Public Health, University of Health and Allied Sciences, Ho, Ghana. ${ }^{6}$ Toxicology and Drug Metabolism Group, Department of Pharmacy, Faculty of Health and Medical Sciences, University of Copenhagen, Copenhagen, Denmark. ${ }^{7}$ Centre for Medical Parasitology, Department of Infectious Diseases, Copenhagen University Hospital (Rigshospitalet), Copenhagen, Denmark.
\end{abstract}

\section{Acknowledgements}

We thank the children and parents/guardians for participation in this study. Also, we thank the project team at Hohoe Municipal Hospital, Albert AdipahYaobotsi, Albert Agordo, Anthony Dongdem, Bless Otoo, Dinah Searyoh, Donald Asimah, Edwin Anyomitse, Eric Agboli, Gideon Kudah, Gideon Kye-Duodu, Joshua Labadah, Joyce Der-Saayeng, Margaret Kweku, Newlove Sonu, Peter Kpiebemane, Rukaya Laryea, Sarah B. Mensah Arab, Shelter Gordor, Vivian Gantuah; the staff at Noguchi Memorial Institute for Medical Research, Alex Danso-Coffie, Betty Bandoh, Frederica Dedo Partey, Gertrude Ecklu-Mensah, Kakra Dickson, William van der Puije, and the staff at CMP, Anja Jensen, Grethe Gomme, Jonathan Glenthøj, Kirsten Pihl Zimling, Lea Barfod, Maiken Høwning Visti, Mette Ulla Madsen and Søren Skov Fredriksen; the staff at the Department of Pharmacy, University of Copenhagen, Peter Bucka and Claus Cornett. Also, many thanks to the clinical staff for their work during the study and the hospital administration at Hohoe Municipal Hospital for allowing us to make us of the hospital facilities.

\section{Competing interests}

The authors declare that they have no competing interests.

\section{Availability of data and materials}

The datasets used and/or analysed during the current study are available from the corresponding author on reasonable request.

\section{Ethics approval and consent to participate}

The study was approved by the Noguchi Memorial Institute for Medical Research Institutional Review Board (NMIMR STC Number: STC Paper 5(1)2013-2014) and by the Ethical Review Committee of the Ghana Health Service (file GHS-ERC 08/05/14). Parents/guardians of all study participants were informed in their local language, Ewe, of the goals, benefits and risks of taking part in the study, and written consent was obtained prior to enrolment.

\section{Funding}

The study was funded by the Danish International Development Assistance, Danida (Grant DFC 12/081RH) and by the Faculty of Health and Medical Sciences, University of Copenhagen. The funders had no role in the study design, data collection and analysis, decision to publish, or preparation of this manuscript.

\section{Publisher's Note}

Springer Nature remains neutral with regard to jurisdictional claims in published maps and institutional affiliations.

Received: 29 Auqust 2018 Accepted: 1 December 2018

Published online: 11 December 2018

\section{References}

1. Halterman JS, Kaczorowski JM, Aligne CA, Auinger P, Szilagyi PG. Iron deficiency and cognitive achievement among school-aged children and adolescents in the United States. Pediatrics. 2001;107:1381-6.

2. Beard JL. Why iron deficiency is important in infant development. J Nutr. 2008;138:2534-6.

3. Lozoff B. Early iron deficiency has brain and behavior effects consistent with dopaminergic dysfunction. J Nutr. 2011;141:740S-6S.

4. Doom JR, Georgieff MK. Striking while the iron is hot: understanding the biological and neurodevelopmental effects of iron deficiency to optimize intervention in early childhood. Curr Pediatr Rep. 2014;2:291-8.

5. Jonker FAM, Boele van Hensbroek M. Anaemia, iron deficiency and susceptibility to infections. J Infect. 2014;69(Suppl 1):S23-7.

6. Nyakeriga AM, Troye-Blomberg M, Dorfman JR, Alexander ND, Bäck R, Kortok $M$, et al. Iron deficiency and malaria among children living on the coast of Kenya. J Infect Dis. 2004;190:439-47.

7. Gwamaka M, Kurtis JD, Sorensen BE, Holte S, Morrison R, Mutabingwa TK, et al. Iron deficiency protects against severe Plasmodium falciparum malaria and death in young children. Clin Infect Dis. 2012;54:1137-44.

8. Jonker FAM, Calis JCJ, van Hensbroek MB, Phiri K, Geskus RB, Brabin BJ et al. Iron status predicts malaria risk in Malawian preschool children. PLOS ONE. 2012;7:e42670.

9. Moya-Alvarez V, Cottrell G, Ouédraogo S, Accrombessi M, Massougbodgi A, Cot M. High iron levels are associated with increased malaria risk in infants during the first year of life in Benin. Am J Trop Med Hyg. 2017;97:497-503.

10. Barffour MA, Schulze KJ, Coles CL, Chileshe J, Kalungwana N, Arguello M, et al. High iron stores in the low malaria season increase malaria risk in the high transmission season in a prospective cohort of rural Zambian children. J Nutr. 2017;147:1531-6.

11. Das BS, Thurnham DI, Das DB. Influence of malaria on markers of iron status in children: implications for interpreting iron status in malariaendemic communities. Br J Nutr. 1997;78:751-60.

12. Kung'u JK, Wright VJ, Haji HJ, Ramsan M, Goodman D, Tielsch JM, et al. Adjusting for the acute phase response is essential to interpret iron status indicators among young Zanzibari children prone to chronic malaria and helminth infections. J Nutr. 2009;139:2124-31.

13. Sazawal S, Black RE, Ramsan M, Chwaya HM, Stoltzfus RJ, Dutta A, et al. Effects of routine prophylactic supplementation with iron and folic acid on admission to hospital and mortality in preschool children in a high malaria transmission setting: community-based, randomised, placebocontrolled trial. Lancet. 2006:367:133-43.

14. Neuberger A, Okebe J, Yahav D, Paul M. Oral iron supplements for children in malaria-endemic areas. Cochrane Database Syst Rev. 2016. https ://doi.org/10.1002/14651858.CD006589.pub4. 
15. Kell DB, Pretorius E. Serum ferritin is an important inflammatory disease marker, as it is mainly a leakage product from damaged cells. Metallomics. 2014;6:748-73.

16. Namaste SM, Aaron GJ, Varadhan R, Peerson JM, Suchdev PS, BRINDA Working Group. Methodologic approach for the biomarkers reflecting inflammation and nutritional determinants of anemia (BRINDA) project. Am J Clin Nutr. 2017:106:333S-47S.

17. Drakesmith $\mathrm{H}$. Next-generation biomarkers for iron status. Nestle Nutr Inst Workshop Ser. 2016:84:59-69.

18. Prentice AM, Doherty CP, Abrams SA, Cox SE, Atkinson SH, Verhoef H, et al. Hepcidin is the major predictor of erythrocyte iron incorporation in anemic African children. Blood. 2012;119:1922-8.

19. Jonker FAM, Calis JCJ, Phiri K, Kraaijenhagen RJ, Brabin BJ, Faragher B, et al. Low hepcidin levels in severely anemic Malawian children with high incidence of infectious diseases and bone marrow iron deficiency. PLOS ONE. 2013;8:e78964.

20. Braithwaite V, Prentice AM, Doherty C, Prentice A. FGF23 is correlated with iron status but not with inflammation and decreases after iron supplementation: a supplementation study. Int J Pediatr Endocrinol. 2012;2012:27.

21. MAVARECA - Malaria vaccine research and capacity building in Ghana. Centre for Medical Parasitology, University of Copenhagen. http://mavar eca.cmp.ku.dk. Accessed 29 Aug 2018.

22. Kweku M, Liu D, Adjuik M, Binka F, Seidu M, Greenwood B, et al. Seasonal intermittent preventive treatment for the prevention of anaemia and malaria in Ghanaian children: a randomized, placebo controlled trial. PLoS ONE. 2008;3:e4000.

23. WHO. Guidelines for the treatment of malaria. 3rd ed. Geneva: World Health Organization; 2015. p. 1-317.

24. Gibbs WN. The methylene blue reduction test: evaluation of a screening method for glucose-6-phosphate dehydrogenase deficiency. Am J Trop Med Hyg. 1974;23:1197-202.

25. Kurtzhals JA, Rodriques O, Addae M, Commey JO, Nkrumah FK, Hviid L. Reversible suppression of bone marrow response to erythropoietin in Plasmodium falciparum malaria. Br J Haematol. 1997;97:169-74.

26. Thurnham DI, Northrop-Clewes CA, Knowles J. The use of adjustment factors to address the impact of inflammation on vitamin $A$ and iron status in humans. J Nutr. 2015:145:1137S-43S.

27. Namaste SM, Rohner F, Huang J, Bhushan NL, Flores-Ayala R, Kupka R, et al. Adjusting ferritin concentrations for inflammation: biomarkers reflecting inflammation and nutritional determinants of anemia (BRINDA) project. Am J Clin Nutr. 2017:106:359S-71S

28. Grant FKE, Suchdev PS, Flores-Ayala R, Cole CR, Ramakrishnan U, Ruth L, et al. Correcting for inflammation changes estimates of iron deficiency among rural Kenyan preschool children. J Nutr. 2012;142:105-11.

29. Thurnham DI, McCabe LD, Haldar S, Wieringa FT, Northrop-Clewes CA, McCabe GP. Adjusting plasma ferritin concentrations to remove the effects of subclinical inflammation in the assessment of iron deficiency: a meta-analysis. Am J Clin Nutr. 2010;92:546-55.
30. Elin RJ, Wolff SM, Finch CA. Effect of induced fever on serum iron and ferritin concentrations in man. Blood. 1977;49:147-53.

31. Birgegård G, Hällgren $R$, Venge $P$, Wide L. Serum ferritin during inflammation. A study on myocardial infarction. Acta Med Scand. 1979;206:361-6.

32. van Iperen CE, Kraaijenhagen RJ, Biesma DH, Bequin Y, Marx JJ, van de Wiel A. Iron metabolism and erythropoiesis after surgery. Br J Surg. 1998:85:41-5.

33. Birgegård G, Hällgren R, Killander A, Strömberg A, Venge P, Wide L. Serum ferritin during infection. A longitudinal study. Scand J Haematol. 1978;21:333-40.

34. Wolf M, White KE. Coupling fibroblast growth factor 23 production and cleavage: iron deficiency, rickets, and kidney disease. Curr Opin Nephrol Hypertens. 2014;23:411-9.

35. David V, Francis C, Babitt JL. Ironing out the cross talk between FGF23 and inflammation. Am J Physiol Renal Physiol. 2017;312:F1-8.

36. Castberg FC, Maretty L, Staalsoe T, Hempel C, Clasen-Linde E, Hviid L, Kurtzhals JAL. Increased Plasmodium chabaudi malaria mortality in mice with nutritional iron deficiency can be reduced by short-term adjunctive iron supplementation. Malar J. 2018;17:34.

37. Beguin Y. Soluble transferrin receptor for the evaluation of erythropoiesis and iron status. Clin Chim Acta. 2003;329:9-22.

38. Skikne BS. Serum transferrin receptor. Am J Hematol. 2008;83:872-5.

39. Menendez C, Quinto LL, Kahigwa E, Alvarez L, Fernandez R, Gimenez N, et al. Effect of malaria on soluble transferrin receptor levels in Tanzanian infants. Am J Trop Med Hyg. 2001;65:138-42

40. Punnonen K, Irjala K, Rajamäki A. Serum transferrin receptor and its ratio to serum ferritin in the diagnosis of iron deficiency. Blood. 1997;89:1052-7.

41. Rehman K, Lötsch F, Kremsner PG, Ramharter M. Haemolysis associated with the treatment of malaria with artemisinin derivatives: a systematic review of current evidence. Int J Infect Dis. 2014:29:268-73.

42. Clark MA, Goheen MM, Fulford A, Prentice AM, Elnagheeb MA, Patel J, et al. Host iron status and iron supplementation mediate susceptibility to erythrocytic stage Plasmodium falciparum. Nat Commun. 2014;5:4446.

43. Maretty L, Sharp RE, Andersson M, Kurtzhals JAL. Intravenous ferric carboxymaltose accelerates erythropoietic recovery from experimental malarial anemia. J Infect Dis. 2012;205:1173-7.

44. Atkinson SH, Armitage AE, Khandwala S, Mwangi TW, Uyoga S, Bejon PA, et al. Combinatorial effects of malaria season, iron deficiency, and inflammation determine plasma hepcidin concentration in African children. Blood. 2014;123:3221-9.

45. Glinz D, Kamiyango M, Phiri KS, Munthali F, Zeder C, Zimmermann MB, et al. The effect of timing of iron supplementation on iron absorption and haemoglobin in post-malaria anaemia: a longitudinal stable isotope study in Malawian toddlers. Malar J. 2014;13:397.

46. WHO Multicentre Growth Reference Study Group. WHO child growth standards: length/height-for-age, weight-for-age, weight-for-length, weight-for-height and body mass index-for-age: methods and development. Geneva: World Health Organization; 2006.

\footnotetext{
Ready to submit your research? Choose BMC and benefit from:

- fast, convenient online submission

- thorough peer review by experienced researchers in your field

- rapid publication on acceptance

- support for research data, including large and complex data types

- gold Open Access which fosters wider collaboration and increased citations

- maximum visibility for your research: over 100M website views per year
}

At BMC, research is always in progress.

Learn more biomedcentral.com/submissions 